\title{
Excess Free Sugar Intake: An Independent Culpable Correlate for the Risk of Hypertension Among Sedentary Occupation Workers
}

\author{
Hanan E Badr* and Omar H Bayoumy \\ Faculty of Science, University of Prince Edward Island, Canada \\ *Corresponding author: Hanan El-Sayed Badr, Faculty of Science, University of Prince Edward Island, Canada
}

\section{ARTICLE INFO}

Received: 幽 September 29, 2021

Published: 慧 October 07, 2021

Citation: Hanan E Badr, Omar H Bayoumy. Excess Free Sugar Intake: An Independent Culpable Correlate for the Risk of Hypertension Among Sedentary Occupation Workers. Biomed J Sci \& Tech Res 39(2)-2021. BJSTR. MS.ID.006278.

Keywords: Free Sugar Intake; High Blood Pressure; Physical Activity; Sedentary Occupation Workers; Kuwait

\begin{abstract}
Background Excess free sugar intake (EFSI) is recently considered as a risk factor for hypertension, which is accidently diagnosed in many people. This study aimed to assess the prevalence of undiagnosed high blood pressure (HBP) among sedentary occupation workers in Kuwait; and to examine significant correlates for the risk of HBP, particularly EFSI. Methods: A cross-sectional study was conducted in 10/17 randomly selected ministries. A convenience sample of 2507 employees completed self-administered questionnaire. Moreover, participants' weight, height, and BP were measured; and their eating habits -including sugar and salt intakes-, and physical activity were assessed. Results: Undiagnosed HBP was prevalent among $66.5 \%$ of participants. Binary logistic regression analysis revealed that EFSI was an independent correlate to the risk of HBP and concealed excess salt intake's role. Additionally, male gender, low educational attainment, low income, and physical inactivity were independent correlates for HBP; and were found to consume more EFSI than their counterparts. Conclusions: EFSI and sociodemographic factors were strongly associated with the risk of developing HBP. Promoting healthy lifestyle at workplace, with focus on employees at high-risk of HBP should be considered. Further studies are recommended to emphasize the autonomous role of EFSI as a risk factor for HBP.
\end{abstract}

\section{Introduction}

High blood pressure (HBP) or "the silent killer" since it shows no symptoms until a significant damage to the blood vessels and/ or the heart take place. Most people don't know that they have HBP, and they are, typically, discovered accidently during routine medical examination, or when developing a hypertension-related complication. Moreover, hypertension is the sturdiest cause of cardiovascular diseases, which are the leading cause of premature death worldwide [1]. Increased salt intake is a well-known risk factor and has a significant role in the pathogenesis of HBP [2]. However, recently in the last few years, the high intake of another white crystal "sugar" is contemplated an etiological factor for the development of hypertension and cardiac diseases independent of salt intake $[3,4]$. There is insufficient evidence in the literature about this association, and there is a gap of knowledge about level of free sugar consumption in the Gulf Region and the Middle East in general. This is the first study to shed the light on this concern in Kuwait, one of the Gulf countries, that has $41 \%$ of mortality rates due to cardiovascular diseases [5]. The current study helps filling in the gap of information and intensifies the evidence about the association between excess free sugar intake (EFSI) and risk of hypertension in Kuwait.

Besides, adverse lifestyle such as unhealthy eating habits and physical inactivity are contributing factors to developing hypertension [6]. For example, inadequate consumption of vegetables, fruits, together with increased fast-food intake, skipping breakfast can pay for overweight/obesity. The latter is a wellknown risk factor for hypertension [7]. It is also documented that practicing one unhealthy habit is associated with other unhealthy ones. Accordingly, it is not surprising that physically inactivity and unhealthy eating patterns mutually overlap as an indication of an 
unhealthy lifestyle among adults $[8,9]$. Several studies examined the risk factors for HBP among adults. However, little is known about whether sedentary workers are exposed to added risk factors. Adults who work in sedentary jobs spend at least 6-7 hours office work, sitting most of the time and consume more snacks than other jobs. Therefore, the premises of this study were to assess the prevalence of HBP among undiagnosed participants, and to examine significant correlates associated with HBP, particularly daily EFSI; among sedentary occupation workers in Kuwait. This study hypothesized an existing association between EFSI and HBP.

\section{Materials and Methods}

\section{Study Design and Study Population}

A cross sectional study was conducted among a convenience sample of 2507 adult employees working at randomly selected 10/17 ministries in Kuwait. In order to obtain a representative sample of ministry employees, the proportional allocation technique was applied and a definite number of employees in each ministry were selected. Furthermore, a computer-generated random numbers were used to define the approached floors and room numbers in the building of each ministry. In addition, all ranks of employment were considered such as departments managers, regular employees, and assisting staff. The response rate was $92.3 \%$.

\section{Ethical Approval}

The study was approved by the Health Sciences Center Ethics Committee for Research (Reference number: VDR/EC/3065). All procedures performed in studies involving human participants were in accordance with the ethical standards of the institutional and/or national research committee and with the 1964 Helsinki declaration and its later amendments or comparable ethical standards. Moreover, the corresponding person in each selected ministry provided a written approval to conduct the study. In addition, informed consent was obtained from all individual participants included in the study. In this consent form, the study aims were clearly explained and information about absence of any risk or any invasive procedure in the study was provided. Confidentiality was assured through using anonymous questionnaires and participation in the study was completely voluntary with no work negative consequences would affect the participant upon refusal to participate.

\section{Study Instruments}

The study employed a self-administered questionnaire to collect data about participants' socio-demographic characteristics, and health status. To assess participants' physical activity (PA) at leisure times, the New Zealand Physical Activity Questionnaire Short Form (NZPAQ-SF) [10] was employed, and thetotal score is divided according to the number of hours spent in PA/week into three categories: relatively inactive $(<2.5$ hours/week); relatively active (2.5-4.9 hours/week); and highly active ( $\geq 5$ hours/week). Anthropometric measurements such as weight and height, and level of blood pressure were assessed by two gender matched trained nurses. For assessing participants' weight, a digital weight scale (Omron HN286 digital personal scale) (Kyoto, Japan) was used to the nearest $1 / 2 \mathrm{~kg}$ with light clothes and bare foot or with stockings. In each location and before use, the scale was calibrated with standard weights. A Seca 217 height rod stadiometer was used to measure the participants' height to the nearest $0.5 \mathrm{~cm}$. Every participant was asked to stand with his/her back against the board with close feet. Body mass index (BMI) was calculated and classified to normal (18.5-24.9), overweight (25-29.9), and obese [30+].

The Omron automatic blood pressure monitor model M6 Comfort (Kyoto, Japan) was used to measure participants' blood pressure. All the manual guidelines were thoroughly followed with daily battery checking. Each participant was sitting comfortably in upright position and supported back, feet flat on the floor, supported arm at heart level. The cuff was placed on bare arm directly above the elbow bend. For each participant, the nurse took two blood pressure readings. The first one was performed after completing the first part of the questionnaire (to be sure that the participant passed at least five minutes before the measurement), the second reading was taken ten minutes later, and before ending the questionnaire (time required for filling out the questionnaire was 15-20 minutes). To avoid any means of participant's stress that can affect the blood pressure measure, the second reading was used for the study. Participants' blood pressure readings were classified according to the American Heart Association [11] to four categories: Normal (<120/80 mm Hg); Elevated (120-129/< 80 mm Hg); Stage I (130-139/80-89 mm Hg); Stage II (140/90 mm Hg or more).

In addition, the "Eating habits section" of the Lifestyle Questionnaire of the Institut de Recherches Cliniques de Montréal [12] was used to assess the diet habits of participants. The Mediterranean Diet Score Tool [13] was used to define the cut off points for daily adequate intake of vegetables, fruits, and sweets. Daily salt intake followed the WHO recommendation (1 teaspoon/ day) [14]. The free sugar intake was calculated as the sum of daily number of added teaspoons of sugar -reported by participants- to tea and coffee drinks. Furthermore, participants' daily consumption of sugar-sweetened beverages (SSBs) such as carbonated beverages, (eg, colas), fruit drinks, and iced tea were also counted. Participants reported average daily number of consumed SSBs was multiplied by eight (average number of teaspoons of sugar in each SSB) according to the American Heart Association [15]. The overall intake of number of teaspoons of sugar (in SSB and that added to hot drinks) was divided according to the AHA. The maximum allowed number of added free sugar in a day is 9 teaspoons for 
males and 6 teaspoons for females [16]. Accordingly, participants were categorized to those with "Adequate intake" (who followed the gender based AHA daily free sugar consumption], and others with "Excess intake" (who exceeded the AHA limits of free sugar intake).

The questionnaire was first designed in English, then translated to Arabic and back translated to English to ensure reliability. Pilot testing of the questionnaire took place among employees from a ministry that was not included in the study to ensure comprehensibility and clarity of the questionnaire. Negligible editing of the questionnaire was recommended.

\section{Statistical Analysis}

Data was collected from July 2018 to December 2018. Data was analyzed using SPSS version 25 (IBM, USA). To examine the association between covariates, Chi-square, student t-test, and Pearson correlation tests were calculated. In order to figure out the correlates associated with HBP (outcome variable) among participants after ruling out the effect of confounders, binary logistics regression was performed. The measured blood pressure (dependent variable) was categorized into two groups: "Normal" and scored as " 0 " and the other three groups of blood pressure (elevated, stage I and II) were categorized as "Hypertension" and scored as "1". A p-value of $<0.05$ and Confidence Interval (CI) of $95 \%$ were considered significant.

\section{Results}

Participants' sociodemographic characteristics according to their level of measured blood pressure are illustrated in Table 1. HBP was significantly negatively associated with the level of monthly income, and the job rank.The participants' health status and level of physical activity are demonstrated in Table 2 . The study-measured blood pressure revealed that only $23.4 \%$ of participants were with normal levels of blood pressure and $66.5 \%$ were with undiagnosed different levels of HBP. About 43\% were with stage I hypertension, and $17.5 \%$ were with stage II hypertension. The mean systolic and diastolic blood pressures of participants were $121.4 \pm 15.0$ and $81.9 \pm 8.0$ respectively. Moreover, the table demonstrated that HBP was directly associated with participants' BMI and inversely associated with the level of physical activity.

Table 1: Sociodemographic characteristics of sedentary occupation workers according to their measured blood pressure in Kuwait $(\mathrm{n}=2507)$.

\begin{tabular}{|c|c|c|c|c|c|c|}
\hline \multirow[b]{2}{*}{ Characteristics } & \multicolumn{5}{|c|}{ Measured blood pressure } & \multirow[b]{2}{*}{ p-value } \\
\hline & $\begin{array}{c}\text { Total } n=2507 \\
100 \% \mathrm{n}(\%)\end{array}$ & $\begin{array}{c}\text { Normal } n=586 \\
23.4 \% n(\%)\end{array}$ & $\begin{array}{c}\text { Elevated } n=403 \\
(16.0 \%) n(\%)\end{array}$ & $\begin{array}{c}\text { Stage In=1080 } \\
43.1 \% n(\%)\end{array}$ & $\begin{array}{c}\text { Stage II } \\
n=438 \\
17.5 \% \mathrm{n}(\%)\end{array}$ & \\
\hline \multicolumn{6}{|c|}{ Age in years } & \multirow{4}{*}{$<0.001$} \\
\hline$<30$ & $707(28.2)$ & $316(44.7)$ & $194(27.4)$ & $163(23.1)$ & $34(4.8)$ & \\
\hline $30-39$ & $1034(41.2)$ & $216(20.9)$ & $172(16.6)$ & $549(53.1)$ & $97(9.4)$ & \\
\hline $40+$ & $766(30.6)$ & $54(7.0)$ & $37(4.8)$ & $368(48.0)$ & $307(40.2)$ & \\
\hline Mean \pm SD & $35.4 \pm 8.4$ & $30.1 \pm 6.3$ & $30.6 \pm 5.9$ & $37.3 \pm 7.6$ & $42.1 \pm 7.8$ & $<0.001$ \\
\hline \multicolumn{6}{|c|}{ Gender } & \multirow{3}{*}{$<0.001$} \\
\hline Males & $1258(50.2)$ & $64(5.1)$ & $179(14.2)$ & $846(67.3)$ & $169(13.4)$ & \\
\hline Females & $1249(49.8)$ & $522(41.8)$ & $224(17.9)$ & $234(18.7)$ & $269(21.6)$ & \\
\hline \multicolumn{6}{|c|}{ Marital status } & \multirow{3}{*}{$<0.001$} \\
\hline Single & $754(30.1)$ & $254(33.7)$ & $182(24.1)$ & $269(35.7)$ & $49(6.5)$ & \\
\hline Ever married & 1753(69.9) & $332(18.9)$ & $221(12.6)$ & $811(46.3)$ & $389(22.2)$ & \\
\hline \multicolumn{6}{|c|}{ Educational attainability } & \multirow{3}{*}{$<0.001$} \\
\hline Less than university & $916(36.5)$ & $304(33.2)$ & $199(21.8)$ & $299(32.6)$ & $114(12.4)$ & \\
\hline University and above & $1591(63.5)$ & $282(17.7)$ & $204(12.8)$ & $781(49.1)$ & $324(20.4)$ & \\
\hline \multicolumn{6}{|c|}{ Level of monthly income (Kuwaiti Dinar) (KD=\$3.3 USD) } & \multirow{4}{*}{$<0.001$} \\
\hline$<500$ & $398(15.9)$ & $47(11.8)$ & $42(10.6)$ & $294(73.8)$ & $15(3.8)$ & \\
\hline $500-1000$ & $1583(63.1)$ & $362(22.9)$ & $301(19.0)$ & $600(37.9)$ & $320(20.2)$ & \\
\hline$>1000$ & $526(21.0)$ & $177(33.7)$ & $60(11.4)$ & $186(35.3)$ & 103(19.6) & \\
\hline \multicolumn{6}{|c|}{ Employment experience (years) } & \multirow{5}{*}{$<0.001$} \\
\hline 5-Jan & $868(34.6)$ & $307(35.5)$ & $200(23.0)$ & $312(35.9)$ & $49(5.6)$ & \\
\hline 10-Jun & $718(28.6)$ & $197(27.4)$ & $117(16.3)$ & $308(42.9)$ & $96(13.4)$ & \\
\hline 15-Nov & $409(16.3)$ & $56(13.7)$ & $55(13.4)$ & $193(47.2)$ & $105(25.7)$ & \\
\hline $16+$ & $512(20.4)$ & $26(5.1)$ & $31(6.1)$ & $267(52.1)$ & 188(36.7) & \\
\hline
\end{tabular}




\begin{tabular}{|c|c|c|c|c|c|c|}
\hline \multicolumn{7}{|c|}{ Job rank } \\
\hline Manager & $301(12.0)$ & $32(10.6)$ & $53(17.6)$ & $126(41.9)$ & $90(29.9)$ & $<0.001$ \\
\hline Employee & $1369(54.6)$ & $362(26.4)$ & $256(18.7)$ & $529(38.6)$ & $222(16.2)$ \\
\hline Assistance staff & $837(33.4)$ & $192(22.9)$ & $94(11.2)$ & $425(50.8)$ & $126(15.1)$ & \\
\hline
\end{tabular}

Table 2: Health status and level of physical activity among sedentary occupation workers according to their measured blood pressure in Kuwait $(n=2507)$.

\begin{tabular}{|c|c|c|c|c|c|c|}
\hline \multirow[b]{2}{*}{ Characteristics } & \multicolumn{5}{|c|}{ Measured blood pressure } & \multirow[b]{2}{*}{ p-value } \\
\hline & $\begin{array}{c}\text { Total } \mathbf{n}=\mathbf{2 5 0 7} \\
\text { n(\%) }\end{array}$ & $\begin{array}{c}\text { Normal n=586 } \\
n(\%)\end{array}$ & $\begin{array}{c}\text { Elevated } n=403 \\
n(\%)\end{array}$ & $\begin{array}{c}\text { Stage I } \\
\mathbf{n}=1080 \\
\mathbf{n}(\%)\end{array}$ & $\begin{array}{c}\text { Stage II } \\
\mathrm{n}=438 \\
\mathrm{n}(\%)\end{array}$ & \\
\hline \multicolumn{6}{|c|}{ Diagnosed Hypertension } & \multirow{3}{*}{$<0.001$} \\
\hline Yes & $253(10.1)$ & $10(1.7)$ & $5(1.2)$ & $73(1.2)$ & $165(37.7)$ & \\
\hline No & $2254(89.9)$ & $576(98.3)$ & 398(98.8) & $1007(98.8)$ & $273(62.3)$ & \\
\hline \multicolumn{6}{|c|}{ Diagnosed Diabetes mellitus } & \multirow{3}{*}{$<0.001$} \\
\hline Yes & $251(10.0)$ & $22(3.8)$ & $20(5.0)$ & $112(10.4)$ & $97(22.1)$ & \\
\hline No & $2256(90.0)$ & $564(96.2)$ & $383(95.0)$ & $968(89.6)$ & $341(77.9)$ & \\
\hline \multicolumn{6}{|c|}{ Diagnosed with at least one other chronic diseases } & \multirow{3}{*}{$<0.001$} \\
\hline Yes & $407(16.2)$ & $31(5.3)$ & $25(6.2)$ & $162(15.0)$ & $189(43.2)$ & \\
\hline No & $2100(83.8)$ & $555(94.7)$ & $378(93.8)$ & $918(85.0)$ & $249(56.8)$ & \\
\hline \multicolumn{6}{|c|}{ BMI } & \multirow{4}{*}{$<0.001$} \\
\hline Normal & $681(27.1)$ & $243(41.4)$ & $176(43.7)$ & 194(18.0) & $68(15.5)$ & \\
\hline Overweight & $937(37.4)$ & $212(36.2)$ & $145(36.0)$ & $412(38.1)$ & $168(38.4)$ & \\
\hline Obese & $889(35.5)$ & $131(22.4)$ & $82(20.3)$ & $474(43.9)$ & $202(46.1)$ & \\
\hline \multicolumn{6}{|c|}{ Level of physical activity } & \multirow{4}{*}{$<0.001$} \\
\hline Relatively inactive & $1196(47.7)$ & $172(29.4)$ & $190(47.1)$ & $622(57.6)$ & $212(48.4)$ & \\
\hline Relatively active & $657(26.2)$ & $132(22.5)$ & $128(31.8)$ & $235(21.8)$ & $162(37.0)$ & \\
\hline Highly active & $654(26.1)$ & $282(48.1)$ & $85(21.1)$ & $223(20.6)$ & $64(14.6)$ & \\
\hline
\end{tabular}

Participants' eating habits according to their level of measured blood pressure is shown in Table 3. The table showed that adverse eating habits were more reported by participants with higher level of blood pressure compared to those with normal blood pressure. Moreover, EFSI showed significant positive correlation with both systolic and diastolic blood pressure of participants ( $\mathrm{r}=0.145$, $\mathrm{p}<0.001$ and $\mathrm{r}=0.167, \mathrm{p}<0.001$ respectively). On the other hand, only $6.7 \%$ of participants reported daily consumption of excess salt intake, insufficient daily vegetable and fruit intake were reported by $89.5 \%$ and $54.4 \%$ respectively. The binary logistic regression of significant correlates associated with HBP after adjusting for other variables is illustrated in Table 4. Relatively older participants (3039 and $40+$ ) were 2.6 and 5.3 times respectively more likely to be at higher risk of HBP, $\mathrm{p}<0.001$ for each. Also, male participants were 15.2 times more likely to have HBP compared to their female counterparts, $\mathrm{p}<0.001$. Moreover, participants with low educational attainability and those with low income $(<500 \mathrm{KD} /$ month) were almost two and five times, respectively, more likely to be at higher risk to have HBP relative to their counterparts. Furthermore, physically inactive participants were 3.16 times more likely to be at higher risk to have HBP relative to the highly active participants $(\mathrm{p}<0.001)$.

Regarding the food habits, the table showed that after adjusting for all eating habits and socio-demographic characteristics, participants who reported EFSI were almost 1.5 times more likely to be at higher risk to have hypertension compared to their correspondence who reported adequate free sugar intake $(\mathrm{p}<0.001)$. 
Table 3: Eating habits of sedentary occupation workers according to their measured blood pressure in Kuwait ( $\mathrm{n}=2507)$.

\begin{tabular}{|c|c|c|c|c|c|c|}
\hline \multirow[b]{2}{*}{ Characteristics } & \multicolumn{5}{|c|}{ Measured blood pressure } & \multirow[b]{2}{*}{ p-value } \\
\hline & $\begin{array}{c}\text { Total } \mathbf{n}=2507 \\
\text { n(\%) }\end{array}$ & $\begin{array}{c}\text { Normal } n=586 \\
n(\%)\end{array}$ & $\begin{array}{c}\text { Elevated } n=403 \\
n(\%)\end{array}$ & $\begin{array}{c}\text { Stage I } \\
\mathbf{n}=1080 \\
\mathbf{n}(\%)\end{array}$ & $\begin{array}{c}\text { Stage II } \\
\mathrm{n}=438 \\
\mathrm{n}(\%)\end{array}$ & \\
\hline \multicolumn{6}{|c|}{ Skip breakfast/week } & \multirow{4}{*}{$<0.001$} \\
\hline 0 times & $878(35.0)$ & $193(32.9)$ & $153(38.0)$ & $433(40.1)$ & $99(22.6)$ & \\
\hline $1-2$ times & $1238(49.4)$ & $312(53.2)$ & $109(27.0)$ & $513(47.5)$ & $304(69.4)$ & \\
\hline$\geq 3$ times & $391(15.6)$ & $81(13.9)$ & $141(35.0)$ & $134(12.4)$ & $35(8.0)$ & \\
\hline \multicolumn{6}{|c|}{ Free daily sugar intake } & \multirow{3}{*}{$<0.001$} \\
\hline Adequate & $923(36.8)$ & $316(53.9)$ & $170(42.2)$ & $316(29.3)$ & $121(27.6)$ & \\
\hline Excess & $1584(63.2)$ & $270(46.1)$ & $233(57.8)$ & $764(70.7)$ & $317(72.4)$ & \\
\hline \multicolumn{6}{|c|}{ Eating fast food meals/week } & \multirow{4}{*}{$<0.001$} \\
\hline$\leq 1$ time & $1035(41.2)$ & $247(42.2)$ & $192(47.6)$ & $400(37.0)$ & $196(44.7)$ & \\
\hline $2-3$ times & $1102(44.0)$ & $292(49.8)$ & $151(37.5)$ & $428(39.6)$ & $231(52.7)$ & \\
\hline$\geq 4$ times & $370(14.8)$ & $47(8.0)$ & $60(18.9)$ & $252(23.3)$ & $11(2.5)$ & \\
\hline \multicolumn{6}{|c|}{ Eating sweets/day* } & \multirow{3}{*}{$<0.001$} \\
\hline$\leq 2$ times & $325(13.0)$ & $103(17.6)$ & $62(15.4)$ & $118(10.9)$ & $42(9.6)$ & \\
\hline$\geq 3$ times & $2182(87.0)$ & $483(82.4)$ & $341(84.6)$ & $962(89.1)$ & $396(90.4)$ & \\
\hline \multicolumn{6}{|c|}{ Salt intake/day** } & \multirow{3}{*}{0.001} \\
\hline Adequate ( $\leq 1$ teaspoon) & $2339(93.3)$ & $558(95.2)$ & $382(94.8)$ & $981(90.8)$ & $418(95.4)$ & \\
\hline Excess ( $\geq 2$ teaspoons) & $168(6.7)$ & $28(4.8)$ & $21(5.2)$ & $99(9.2)$ & $20(4.6)$ & \\
\hline \multicolumn{6}{|c|}{ Fruit intake/day* } & \multirow{3}{*}{$<0.001$} \\
\hline Insufficient (< 3 servings) & $1363(54.4)$ & $411(70.1)$ & $222(55.1)$ & $520(48.1)$ & $210(47.9)$ & \\
\hline Adequate ( $\geq 3$ servings) & $1144(45.6)$ & $175(29.9)$ & $181(44.9)$ & $560(51.9)$ & $228(52.1)$ & \\
\hline \multicolumn{6}{|c|}{ Vegetable intake/day* } & \multirow{3}{*}{$<0.001$} \\
\hline Insufficient (< 4 servings) & $2244(89.5)$ & $523(89.2)$ & $328(81.4)$ & $1015(94.0)$ & $378(86.3)$ & \\
\hline Adequate ( $\geq 4$ servings) & $263(10.5)$ & $639(10.8)$ & $75(18.6)$ & $65(6.0)$ & $60(13.7)$ & \\
\hline
\end{tabular}

Note: * Mediterranean Diet Score

**World Health Organization

Table 4: Binary logistic regression of significant correlates associated with the risk of hypertension among sedentary occupation workers in Kuwait ( $\mathrm{n}=2507)$.

\begin{tabular}{|c|c|c|c|c|c|c|}
\hline & \multicolumn{3}{|c|}{ Non-adjusted Odds Ratio (OR) } & \multicolumn{3}{|c|}{ Adjusted OR to risk of hypertension* } \\
\hline & OR & p-value & $95 \% \mathrm{CI}$ & OR & p-value & $95 \% \mathrm{CI}$ \\
\hline \multicolumn{7}{|c|}{ Adjusted OR to risk of hypertension* } \\
\hline Age & & $<0.001$ & & & $<0.001^{\mathrm{a}}$ & \\
\hline$<30$ & 1 & --- & $\left(\mathrm{RG}^{*}\right)$ & 1 & --- & (RG) \\
\hline $30-39$ & 3.11 & $<0.001$ & $(2.53-3.83)$ & 2.62 & $<0.001^{\mathrm{a}}$ & $(1.83-3.74)$ \\
\hline $40+$ & 10.74 & $<0.001$ & $(7.87-14.65)$ & 5.3 & $<0.001^{\mathrm{a}}$ & $(2.99-9.41)$ \\
\hline \multicolumn{7}{|c|}{ Gender } \\
\hline Males & 13.4 & $<0.001$ & $(10.18-17.64)$ & 15.23 & $<0.001^{\mathrm{a}}$ & $(10.21-22.70)$ \\
\hline Females & 1 & --- & $(\mathrm{RG})$ & 1 & --- & $(\mathrm{RG})$ \\
\hline \multicolumn{7}{|c|}{ Educational attainability } \\
\hline Less than university & 1 & --- & $(\mathrm{RG})$ & 1.99 & $<0.001^{\mathrm{a}}$ & $(1.55-2.54)$ \\
\hline University and above & 2.31 & $<0.001$ & $(1.92-2.87)$ & 1 & --- & (RG) \\
\hline $\begin{array}{l}\text { Level of monthly income (Kuwaiti Dinar) (1 } \\
\text { KD }=\$ 3.3 \text { USD) }\end{array}$ & & $<0.001$ & & & $<0.001^{\mathrm{a}}$ & \\
\hline
\end{tabular}




\begin{tabular}{|c|c|c|c|c|c|c|}
\hline$<500$ & 2.13 & 0.001 & $(1.39-3.23)$ & 4.69 & $<0.001^{\mathrm{a}}$ & $(2.79-7.89)$ \\
\hline $500-1000$ & 0.57 & $<0.001$ & $(0.44-0.74)$ & 1.37 & 0.086 & $(0.96-1.95)$ \\
\hline$>1000$ & 1 & --- & (RG) & 1 & --- & (RG) \\
\hline Level of physical activity & & $<0.001$ & & & $<0.001^{\mathrm{b}}$ & \\
\hline Relatively inactive & 2.5 & $<0.001$ & $(1.89-3.32)$ & 3.16 & $<0.001^{\mathrm{b}}$ & $(2.26-4.43)$ \\
\hline Relatively active & 0.56 & $<0.001$ & $(0.45-0.69)$ & 1.03 & 0.808 & $(0.80-1.34)$ \\
\hline Highly active & 1 & --- & (RG) & 1 & --- & (RG) \\
\hline \multicolumn{7}{|c|}{ Food habits } \\
\hline \multicolumn{7}{|c|}{ Free sugar intake } \\
\hline Adequate & 1 & --- & (RG) & 1 & --- & $(\mathrm{RG})$ \\
\hline Excess & 1.76 & $<0.001$ & $(1.46-2.13)$ & 1.49 & $0.001^{c}$ & $(1.17-1.89)$ \\
\hline
\end{tabular}

Note: *RG: Reference Group.

${ }^{a}$ Model I: Covariates were age, gender, monthly income, educational attainability, and marital status.

${ }^{b}$ Model II: Covariates in Model I and BMI, level of physical activity,

'Model III: Covariates in Model II and eating habits (excess salt intake, excess free sugar intake, skipping breakfast, fast food, fruit and vegetable intake).

\section{Discussion}

This study exposed a thoughtful finding related to the prevalent undiagnosed elevated levels of blood pressure among sedentary occupation workers in Kuwait. Although only $10 \%$ of participants reported diagnosed hypertension, six and half folds that number were discovered with HBP readings that required further follow up and assessment by a physician. Parallel to this result, this study also explored that unfavorable sugar consumption could be culpable of this high levels of blood pressure.

\section{Excess Free Sugar Intake and Risk of Hypertension}

The study revealed that daily EFSI stood strongly a significant independent factor associated with the risk of HBP after adjusting for other covariates including excess daily salt intake. The later showed an Odds Ratio (OR) of 3.2 at the univariate level of analysis; however, after adding the daily EFSI, the influence of excess salt intake disappeared. It is important to add that the risk of hypertension would be greatly augmented should the exact total amount of daily sugar intake included in the consumed sweets and refined carbohydrates were added. This finding is of utmost importance because although excess salt intake as a risk factor of hypertension is well documented $[17,18]$, the sturdier influence of excess sugar intake is underestimated. This finding is in consonance with the results of a preceding study, which concluded that excess daily sugar intake is associated with increased systolic and diastolic blood pressure [4]. Additionally, a previous study reported a positive gradual significant association between carbonated sugarsweetened beverages intake and level of hypertension, which is matching the positive correlation between excess sugar intake and systolic and diastolic blood pressures in this study [19]. Moreover, a recent study considered sugar -not salt- as an etiological factor for hypertension and cardio-metabolic diseases and referred to the importance of changing the guidelines to greatly consider sugar white crystal intake as a risk factor for hypertension rather than only the salt white crystal [3]. This study is in agreement with this important referral as the compass of the dangerous effects of white crystals should change the direction and point towards the new culprit, which is excess sugar intake and not excess salt intake. This study finding is matching the study hypothesis and is an addition to the scanty published information about the serious association between excess free sugar intake and hypertension. Furthermore, the nature of sedentary work may indirectly increase the consumption of unhealthy food such as convenience foods, soft drinks and sugary snacks [20].

\section{Who are The Victims at Higher Risk of HBP?}

This study revealed that older age, male gender, low level of educational attainability, low level of income, and being physically inactive were independent correlates for the risk of hypertension. Employment experience was not added to the regression analysis model for HBP because age was included in the model to avoid collateral yield as both variables are strongly related to each other. This study findings emphasized the well-known independent positive association between the inevitable aging and risk of hypertension. This finding is well-documented in preceding studies $[21,22]$. More in depth analysis revealed that longer years of employment -parallel to aging- was inversely associated with EFSI. This finding is supported by a Meta-analysis study that concluded that there is an overall decrease in added sugar intake from adolescence to adulthood especially in sugary drinks and beverages [23]. This might be elucidated in terms of people at this relatively 
later stage of life may have health problems that necessitate changes in eating behaviours such as restricting sugar intake, together with physiological changes associated with getting older that may change their metabolic rate along with changes in appetite and craving for sugar. This finding is worth further research to figure out physiological and psychosocial factors related to reduction in sugar intake and in SSBs amid older people.

Moreover, male gender was found to be an autonomous factor for severe risk for HBP. This finding is supporting gender disparities in hypertension status in previous studies. In a preceding study amid more than 14 thousand young adults, Everett and Zagacova [24] reported that hypertension was prevalent in men $(27 \%)$ as more than double as in women (12\%). In addition, it is established that not only the incidence of hypertension but also its severity is more evident among men compared to women of the same age until they hit the sixth decade of life, thereafter the differences are negligible $[25,26]$. Remarkably, further analysis to figure out whether there was a gender differences in EFSI revealed that men consumption of sugar was significantly higher than females, which is concluded from the United Kingdom Biobank study about gender differences in macronutrient intake [27]. Moreover, a study among first-year college students indicated that male students are less confident that they can replace sugar-sweetened beverages with water than female students. The gender disparity in macronutrient consumption might be explained by gender differences in appetite sensations and overfeeding [28]. Women have excess sensitivity to macronutrient changes and to overfeeding, which lead to higher changes in the appetite sensitivity and therefore less energy intake in women than men [29]. Furthermore, Davy, Benes, \& Driskell [30] reported that females have more nutrition knowledge and better healthier eating habits than males. These gender differences are proved to have a neural pattern and brain areas related to gender different neurocognitive functions. Exposure to high caloric food showed significant greater activation of cortical areas that are involved in behavioral and cognitive control in women than men [31].

An additional finding in this study was the independent role of low income and educational attainability as significant correlates for the risk of hypertension. This was an anticipated result as both low level of education and income are closely sequenced [32]. Further analysis revealed that these study participants showed also higher prevalence of overweight and obesity relative to their counterparts who reported the highest level of income. Disadvantageous individuals with limited financial resources expose them to unhealthy food choices predominantly low in vegetables and fruits, high in simple carbohydrates and sugar intake to reach the satiety level $[1,33]$. Moreover, they have less access to preventive healthcare measures, fewer chances to participate in weight losing programs or physical activity facilities [34]. Furthermore, they are exposed to different degrees of psychosocial mental stressors that worsen their obesity -overeating of mostly unhealthy food as an adverse coping mechanism- and increased risk of hypertension [33].

Another finding in this study was that physical inactivity is identified as an independent significant correlate to higher risk of HBP. This finding is supported by a number of previous studies that consistently documented the association between physical inactivity and risk of hypertension. For instance, a meta-analysis of prospective cohort studies concluded that there is a significant converse dose-response relationship between level of recreational physical activity, and not occupational physical activity, and risk of hypertension [35]. Additionally, the profitable effect of physical activity in lowering systolic and diastolic blood pressure is wellestablished [6,36,37]. Furthermore, supplementary analysis showed that physical inactive participants were more likely to consume excess sugar on daily basis relative to their counterparts who were physically active. This imperative finding is explained as there is a relation between individual's mood and the regulation of food intake and physical activity behavior. The high intake of simple carbohydrates -that is transferred rapidly to high blood sugar levelis associated with feeling of easy fatigability and low energy that could have a negative effect on person's ability to practice physical activity and would favor sedentary behaviours [38,39]. Moreover, the concept of a compensatory response to high sugar intake by a fiber rich diet that stabilizes blood sugar and insulin levels is formerly reported [40]. This might explain the less compensatory response experienced by this study's participants who reported low fiber intake as well and therefore the less capability for involvement in physical activity. In addition, increased intake of SSBs is found to be independently associated with insulin resistance, which cause type 2 diabetes mellitus [2].

\section{Limitations}

Although the study has revealed important findings and associations, it is thoughtful to highlight some study limitations. The nature of the study as cross-sectional could not estimate the temporal causality of the association between EFSI and hypertension. In addition, having a convenience study sample might cause a selection bias, which might overlook participants with different eating habits or physical activity.

\section{Conclusions}

Regular consumption of excess free sugar was associated with increased risk of HBP among sedentary occupation workers in Kuwait. Socio-demographic and physical inactivity were connected to EFSI and to the risk of HBP as well. Future prospective cohort studies that are able to emphasize and accentuate the role of EFSI in increasing the risk of HBP are necessary. In addition, further 
qualitative studies designed to explore the cultural and social factors associated with gender differences in EFSI and diet habits are warranted to better understand its diverse impacts on health outcome in men and women. Health promotion programs at workplaces -exceptionally sedentary occupations- are essential to improve the awareness of workers about healthy food choices and the danger of excess consumption of free sugar and SSBs on health. Furthermore, enhancing physical activity at workplaces to mitigate workers' recreational physical inactivity should be a thoughtful approach. The findings of this study may aid occupational health planners and decision makers to improve the health status and lifestyle of a big sector of occupational workers. Workplaces should be an outstanding opportunity for the availability of healthy food choices and snacks that will help workers to, gradually, develop a healthy lifestyle. The latter is the key to better health outcomes including reduction in prevalence of hypertension.

\section{Disclosure of Interest}

The authors report no conflict of interest.

\section{Financial Support}

This work was supported by the [Kuwait Foundation for the Advancement of Sciences (KFAS)] under Grant [PR17-11BS-01].

\section{References}

1. (2020) World Health Organization. Hypertension.

2. Stolarz-Skrzypek K (2011) Sugar and salt in the pathogenesis of elevated blood pressure. Hypertension 57(4): 676-678.

3. Di Nicolantonio JJ, Lucan SC (2014) The wrong white crystals: not salt but sugar as aetiological in hypertension and cardiometabolic disease. Open Heart 1(1).

4. Mansoori S, Kushner N, Suminski RR, Farquhar WB, Chai SC (2019) Added Sugar Intake is Associated with Blood Pressure in Older Females. Nutrients 11(9): 2060.

5. (2020) World Health Organization. "Kuwait."

6. Hegde SM, Solomon SD (2015) Influence of physical activity on hypertension and cardiac structure and function. Curr Hypertens Rep 17(10): 77

7. Fuhrman J (2018) The hidden dangers of fast and processed food. Am J Lifestyle Med 12(5): 375-381.

8. Sharif MZ, Rizzo S, Marino E, Belin TR, Glik DC, et al. (2016) The association between self-rated eating habits and dietary behavior in two Latino neighborhoods: Findings from Proyecto Mercado FRESCO. Prev Med Rep 3: 270-275.

9. Jezewska-Zychowicz M, Gębski J, Guzek D, Świątkowska M, Stangierska D, et al. (2018) The associations between dietary patterns and sedentary behaviors in Polish adults (LifeStyle study). Nutrients 10(8): 1004.

10. Mackay LM, Schofield GM, Schluter PJ (2007) Validation of self-report measures of physical activity: a case study using the New Zealand Physical Activity Questionnaire. Res Q Exerc Sport 78(3): 189-196.
11. Greenland P, Peterson E (2017) The new 2017 ACC/AHA guidelines "up the pressure" on diagnosis and treatment of hypertension. JAMA 318(21): 2083-2084.

12.(2020) Institut de recherches cliniques de Montréal. "Lifestyle questionnaire."

13. (2020) Nutrition Program, Hamilton Family Health Team. "Mediterranean Diet Scoring Tool."

14. (2020) World Health Organization. "Salt reduction."

15. (2020) American Heart Association. "Added sugars."

16. Johnson RK, Appel LJ, Brands M, Howard BV, Lefevre M, et al. (2009) Dietary sugars intake and cardiovascular health: a scientific statement from the American Heart Association. Circulation 120(11): 1011-1020.

17. Alderman MH (2010) Reducing dietary sodium: the case for caution. JAMA 303(5): 448-449.

18. Ha SK (2014) Dietary salt intake and hypertension. Electrolyte Blood Press 12(1): 7-18.

19. Song HJ, Paek YJ, Choi MK, Yoo K-B, Kang JH, et al. (2017) Gender Differences in the relationship between carbonated sugar-sweetened beverage intake and the likelihood of hypertension according to obesity. Int J Public Health 62(5): 573-581.

20. Escoto K, Laska M, Larson N, Neumark-Sztainer D, Hannan P (2012) Work Hours and Perceived Time Barriers to Healthful Eating Among Young Adults. Am J Health Behav 36(6): 786-796.

21. Pinto E (2007) Blood pressure and ageing. Postgrad Med J 83(976): 109114.

22. Lionakis N, Mendrinos D, Sanidas E, Favatas G, Georgopoulou M (2012) Hypertension in the elderly. World J Cardiol 4(5): 135.

23. Winpenny EM, Penney TL, Corder K, White M, van Sluijs E (2017) Changes in consumption of added sugars from age 13 to 30 years: a systematic review and meta-analysis of longitudinal studies. Obes Rev 18(11):1336-1349.

24. Everett B, Zajacova A (2015) Gender differences in hypertension and hypertension awareness among young adults. Biodemogr Soc Biol 61(1):1-17.

25. Song JJ, Ma Z, Wang J, Chen L-X, Zhong JC (2020) Gender differences in hypertension. J Cardiovasc Transl Res 13(1): 47-54.

26. Reckelhoff JF (2018) Gender differences in hypertension. Curr Opin Nephrol Hypertens 27(3): 176-181.

27. Bennett E, Peters SA, Woodward M (2018) Sex differences in macronutrient intake and adherence to dietary recommendations: findings from the UK Biobank. BMJ Open 8(4): e020017.

28. Bruce MA, Beech BM, Thorpe Jr RJ, Mincey K, Griffith DM (2017) Racial and gender disparities in sugar consumption change efficacy among first-year college students. Appetite 109: 33-39.

29. Bédard A, Hudon AM, Drapeau V, Corneau L, Dodin S, et al. (2015) Gender differences in the appetite response to a satiating diet. J Obes.

30. Davy SR, Benes BA, Driskell JA (2006) Sex differences in dieting trends, eating habits, and nutrition beliefs of a group of midwestern college students. J Am Diet Assoc 106(10): 1673-1677.

31. Manippa V, Padulo C, Van der Laan Laura N, Brancucci A (2017) Gender differences in food choice: effects of superior temporal sulcus stimulation. Front Hum Neurosci 11: 597. 
32. Ferguson HB, Bovaird S, Mueller MP (2007) The impact of poverty on educational outcomes for children. Paediatr Child Health 12(8): 701 706.

33. Huckabay L, Reynolds GL, Fisher DG, Odell A, Dyo M (2016) Hypertension in a low-income and homeless community sample. J Comm Med Health 6: 399.

34. Ewald DR, Bond SH, Haldeman LA (2017) Hypertension in low-income adolescents. Glob Pediatr Health 4: 2333794X17741819.

35. Huai P, Xun H, Reilly KH, Wang Y, Ma W, et al. (2013) Physical activity and risk of hypertension: a meta-analysis of prospective cohort studies. Hypertension 62(6): 1021-1026.

36. Cornelissen VA, Smart NA (2013) Exercise training for blood pressure: a systematic review and meta-analysis. J Am Heart Assoc 2(1): e004473.

ISSN: 2574-1241

DOI: 10.26717/BJSTR.2021.39.006278

Hanan E Badr. Biomed J Sci \& Tech Res

(C) This work is licensed under Creative

Submission Link: https://biomedres.us/submit-manuscript.php
37. Carlson DJ, Dieberg G, Hess NC, Millar PJ, Smart NA (2014) Isometric exercise training for blood pressure management: a systematic review and meta-analysis. Paper presented at the Mayo Clinic Proceedings 89: 327-334.

38. Ranjit N, Evans MH, Byrd-Williams C, Evans AE, Hoelscher DM (2010) Dietary and activity correlates of sugar-sweetened beverage consumption among adolescents. Pediatrics 126(4): e754-761.

39. Thayer RE (2003) Calm energy: How people regulate mood with food and exercise. Oxford University Press, USA.

40. O’Reilly GA, Belcher BR, Davis JN, Martinez LT, Huh J, et al. (2015) Effects of high-sugar and high-fiber meals on physical activity behaviors in Latino and African American adolescents. Obesity 23(9): 1886-1894.

$\begin{array}{ll}\text { BIOMEDICAL } & \text { Assets of Publishing with us } \\ \text { RESEARCHES } & \text { - Global archiving of articles } \\ & \text { - Immediate, unrestricted online access } \\ & \text { - Rigorous Peer Review Process } \\ & \text { - Authors Retain Copyrights }\end{array}$

